Brit. J. industr. Med., 1953, 10, 41.

\title{
A FIELD STUDY OF OCCUPATIONAL DEAFNESS*
}

\author{
BY \\ COLIN M. JOHNSTON
}

(RECEIVED FOR PUBLICATION FEBRUARY 20, 1952)

Fosbroke (1830-31) described deafness in blacksmiths since when there have been many investigations of deafness caused by noise in industry. But there are still many questions of practical importance to the industrial medical officer as yet unanswered. He needs to know how loud a noise must be to cause deafnesss, how to measure noise, and the methods of protecting the workman's hearing where the noise is very loud. These questions cannot be answered simply as there are many factors to be considered, the more important of which are the duration of exposure to noise, its loudness when it reaches the ear, and the susceptibility of the ear to damage (Perlman, 1945).

If a group of men have worked in a loud but steady noise for the same number of years the effects on the hearing of the men will vary widely. Thus it is not possible to give a precise level of noise above which hearing will be impaired. Bunch (1942) and MacLaren and Chaney (1947) agree that noise of an average overall value of $70 \mathrm{db} \dagger$ above a standard reference intensity of 0.0002 dyne $/ \mathrm{sq} . \mathrm{cm}$. is innocuous and that a noise of $100 \mathrm{db}$ or more greatly increases the incidence of impaired hearing.

The assessment of the hearing loss produced by acoustic trauma requires a method which will exclude deafness due to other causes. Larsen (1939), Fowler (1928), Bunch (1937), Perlman (1945), Nussdorfer (1942), Maclaren and Chaney (1947), and Weiss (1947) agree that a circumscribed loss of hearing in the high tones, $3,000-6,000$ c.p.s., the so-called " $C_{5}$ dip," is to a certain extent typical of traumatic deafness. It is known, however, that this circumscribed hearing loss may be due to other

*Based on a report to the Medical Research Council's Committee *Based on a report to the Medical Research Cou
on the Medical and Surgical Problems of Deafness.

†Decibel (db) is the unit of intensity of sound. In Great Britain it is usually applied to the measurement of pure tones only. For the measurement of the loudness of noise the phon may be employed. For a " noise" of a frequency of 1,000 c.p.s. (cycles per second) the fecibel and phon are identical. For noise, which consists of a mixture of pure tones of different frequencies, a subjective comparison is made with a pure tone of 1,000 c.p.s. Hence the phon is not a physical unit of energy but an approximate expression of the loudness of noise as heard by the observer. In the American literature the decibe is also used to describe the loudness of noise. causes. As Caussé and Falconnet (1947) state, it is simply the expression of a special fragility in this region of the auditory spectrum. Nevertheless it is probable that a well marked loss of hearing in the 3,000-6,000 c.p.s. frequency range with markedly smaller losses in the other regions of the auditory spectrum, particularly in the region above 6,000 c.p.s., is pathognomonic of traumatic deafness. Weiss (1947) described the development of the $\mathrm{C}_{5}$ dip and MacLaren and Chaney (1947) classified the severity of their cases according to the development of the " dip ".

\section{Present Investigation}

The investigation was made between June, 1948, and May, 1949, in three factories in the Birmingham area (Messrs. Edwin Danks Ltd. of Oldbury, John Garrington and Sons Ltd., of Bromsgrove, and Guest Keen and Nettlefold Ltd., of Birmingham). The manufacturing processes carried out in these factories gave rise to many types of noise, intermittent or continuous, and with various proportions of low and high frequencies. The National Physical Laboratory gave their cooperation and carried out a full series of noise level measurements.

Boiler Making.-For chipping, caulking, and riveting a portable compressed air hammer in which various tools can be mounted is used. The hammers weigh from 7 to $15 \mathrm{lb}$. and they deliver up to 600 blows per minute. The light hammers give a rapid succession of light blows and are used for caulkingthe operation in which the edges of a rivet or a plate are turned in to make a steam-tight joint. The medium and heavy hammers are mainly used for riveting or chipping.

When riveting, the early stages of forming the head will be relatively quiet when the hammer touches only the heat-softened rivet, but in the later stages when the edge of the tool touches the part being riveted hard metal meets hard metal and more noise is produced. On certain types of work, particularly shipbuilding, several hảmmers are 
often in use simultaneously and the noise is conducted by metal throughout the fabric. Although the peak noise levels are no higher in shipbuilding, the workman is more continuously subjected to noise of a traumatizing intensity than his fellow in the boiler shop. Of the two methods of joining together steel sheets, wellding, which necessitates the chipping of excess metal, is just as noisy as riveting. In pneumatic riveting the riveter is assisted by a "holder-up " or " backer-up" who inserts the rivet and exerts counter pressure with a heavy tool or another pneumatic hammer whilst the head is being formed. When riveting boilers the " holder-up" works inside the boiler and is therefore exposed to more noise than the riveter.

Plate Fitting.- In this work the plates and end of a boiler are assembled for riveting or welding. Minor adjustments are made to the curve of a part by hammering with a heavy sledge hammer. With certain jobs the noise levels from hard hammering may be intense, but the workman is exposed for shorter periods to more intense noise than the chipper or riveter.

Other processes include welding, template making, shearing, bending, drilling. By themselves these operations make relatively little noise but those who do this work are subjected to the noise of pneumatic tools and hard hammering, usually at a distance of several yards but occasionally in close proximity.

Drop Forge Industry.-Red hot steel ingots are forged by stamping hammers in dies. The lower half of the die rests on a firm foundation and the upper half is fixed to the lower surface of a weight of up to $2 \frac{1}{2}$ tons. The weight is raised to a height of two to six feet, according to the strength of blow required and allowed to drop by gravity; with the steam hammer it is aided by steam pressure. The ingot is roughly shaped in one part of the die by several light blows and is then placed on another part of the die where harder blows are given to form the final shape. The last blow is the hardest and emits a metallic ring when the two halves of the die come in contact. There is also a continual roar produced by oil-fired furnaces used for heating the ingots and a high-pitched squeal or various clanking noises of the hammers. The work is carried out in long sheds where from seven to 15 hammers of various sizes are in continuous use. The noise, the heat of the furnaces and ingots, the continual lifting of heavy forgings, together with the dusty, smoke-laden atmosphere, make the trade, although well paid, extremely arduous. The majority of the workmen seek less strenuous employment after the age of 40 .

Screw Manufacture.-In the shop studied, steel screws for wood work were being made on automatic machines. The blank for the screw is made from wire of appropriate thickness on " heading" machines. The "turning" section trims the head of the blank and cuts the " nick" or slot for the screw driver. Finally the thread or "worm" of the screw is cut on an automatic lathe. The noise in all sections is of a fairly constant intensity, being highest in the heading section and lowest in the turning section. Many of the operatives in the turning section, however, work close to the heading machines.

\section{Method of Examination of Subjects}

At two factories disused underground air raid shelters were fitted with double doors. These shelters were more than $\mathbf{5 0}$ yards from the nearest workshop and, apart from occasional and infrequent rumbling noises of passing traffic, ambient noise was at a low level. At another factory the workers were examined in a quiet room in the factory medical department situated 100 yards away from the nearest workshop.

All the subjects came straight from their work and after a preliminary explanation of the purpose of the investigation and the recording of their answers to a set questionnaire, underwent a short examination of the ears, nose, and throat. Cerumen, if present, was removed and the hearing was then tested by tuning fork (C512), speech, watch tick, and pure tone audiometry. For speech tests the subject sat with the ear being tested towards the observer, blocking the opposite ear by pressure on the tragus. Mixed letters and numbers were read in a soft (residual air) whisper and a conversational voice.

The following list of mixed numbers and letters were read in groups of three :

$\begin{array}{llll}\text { X2C } & \text { 4AZ } & \text { SA5 } & \text { U8G } \\ \text { 1SN } & \text { M7D } & \text { L85 } & \text { 7BN } \\ \text { 83Y } & \text { 09F } & \text { 3H6 } & \text { X9E } \\ \text { LP6 } & \text { 3KI } & \text { V4Q } & \text { 82C }\end{array}$

The maximum distance at which two or more groups of three numbers or letters could be correctly repeated was recorded for each ear separately. Masking was employed where necessary.

Pure tone audiometry was made with a " maico D5" audiometer by air conduction only, using a single ear piece. This latter test was started within 20 to 30 minutes of the subject leaving his place of work. The hearing was tested at frequencies of 
$64,128,256,512,1,024,2,048,2,896,4,096,5,792$, 8,192 and 11,584 c.p.s. (The maximum calibrated output of this instrument is $100 \mathrm{db}$ at all frequencies, except 128 and 11,584 c.p.s. where it is $70 \mathrm{db}$, and at $256,5,792$ and 8,192 c.p.s. where it is $80 \mathrm{db}$.)

\section{Results of Hearing Tests}

Two hundred and nineteen workers were examined, but in 28 bilateral ear disease of an infective or degenerative origin not due to acoustic trauma was found, leaving 191 for consideration.

Figs. 1 to 7 show the relation between the duration of work in the trades studied and the hearing loss of the better ear to speech at conversational level. They show that after any given period of exposure to noise the workers in each occupational group show wide variations in the degree of damage to their hearing. Although a high proportion of the workers in each of the factories visited was examined, (all the chippers, riveters, and heading machinists were examined) the numbers in each group are small and precise conclusions are not possible.

The results shown in Figs. 1 to 7 are summarized in Tables 1 and 2. From Table 1 it will be seen that the number of men with more than 20 years' exposure who were unable to hear a conversational

TABLE 1

NO. OF MEN WITH HEARING LOSS AFTER MORE THAN 20 YEARS' EXPOSURE IN DIFFERENT TRADES RELATED TO INTENSITY OF NOISE

\begin{tabular}{|c|c|c|c|c|c|}
\hline \multicolumn{2}{|c|}{ Occupation } & $\begin{array}{c}\text { Noise Level } \\
\text { (phons) }\end{array}$ & $\begin{array}{l}\text { Total } \\
\text { No. of } \\
\text { Men }\end{array}$ & \multicolumn{2}{|c|}{$\begin{array}{l}\text { No. of Men with } \\
\text { Hearing Loss }\end{array}$} \\
\hline \multicolumn{2}{|c|}{ Chippers and riveters } & \multirow[b]{2}{*}{$\begin{array}{c}\text { More than } 130 \\
117-130 \\
130 \\
108-112 \\
90-114 \\
105-108 \\
100-101\end{array}$} & \multirow[b]{2}{*}{$\begin{array}{l}12 \\
11 \\
12 \\
14 \\
12 \\
13 \\
24\end{array}$} & $I^{*}$ & II \\
\hline $\begin{array}{l}\text { Chippers and } r \\
\text { Stampers } \quad . \\
\text { Platers } \\
\text { Headers } \\
\text { Welders, etc. } \\
\text { Wormers } \\
\text { Turners } \quad .\end{array}$ & $\begin{array}{l}\text { ters } \\
\ldots \\
\therefore \\
\cdots \\
\cdots\end{array}$ & & & $\begin{array}{l}9 \\
7 \\
6 \\
4 \\
2 \\
1 \\
0\end{array}$ & $\begin{array}{r}11 \\
9 \\
7 \\
5 \\
4 \\
1 \\
1\end{array}$ \\
\hline
\end{tabular}

${ }^{*} \mathrm{I}=$ unable to hear conversational voice at 3 feet.

II = unable to hear conversational voice at 3 feet

TABLE 2

NO. OF MEN WITH HEARING LOSS AFTER LESS THAN 20 YEARS' EXPOSURE IN DIFFERENT TRADES RELATED TO INTENSITY OF NOISE

\begin{tabular}{|c|c|c|c|c|}
\hline Occupation & $\begin{array}{c}\text { Noise Level } \\
\text { (phons) }\end{array}$ & $\begin{array}{l}\text { Total } \\
\text { No. of } \\
\text { Men }\end{array}$ & \multicolumn{2}{|c|}{$\begin{array}{l}\text { No. of Men with } \\
\text { Hearing Loss }\end{array}$} \\
\hline & & & I & II \\
\hline \begin{tabular}{lll} 
Chippers and & \multicolumn{3}{l}{ riveters } \\
Stampers &. & $\ldots$ \\
Platers &. & $\ldots$ \\
Headers &. &. \\
Welders, etc. & & $\ldots$ \\
Wormers &. & $\ldots$ \\
Turners &. & $\ldots$
\end{tabular} & $\begin{array}{c}\text { More than } 130 \\
117-130 \\
130 \\
108-112 \\
90-114 \\
105-108 \\
100-101\end{array}$ & $\begin{array}{r}2 \\
37 \\
8 \\
6 \\
18 \\
13 \\
9\end{array}$ & $\begin{array}{l}0 \\
4 \\
1 \\
0 \\
0 \\
0 \\
0\end{array}$ & $\begin{array}{l}0 \\
7 \\
2 \\
2 \\
0 \\
1 \\
0\end{array}$ \\
\hline
\end{tabular}

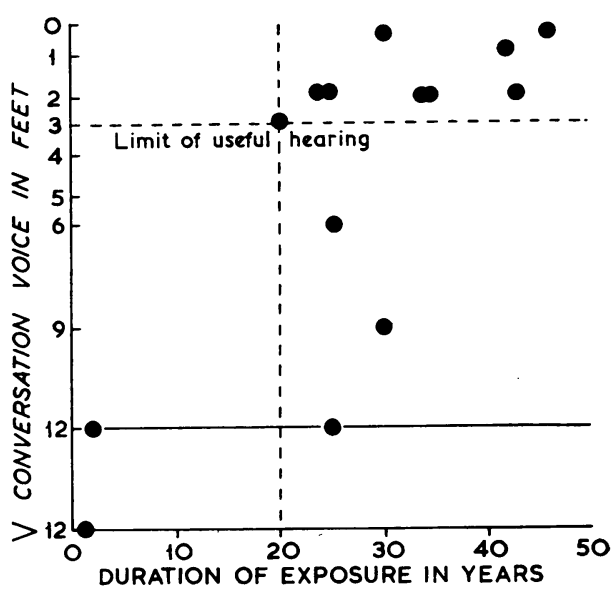

Fig. 1-Chippers and riveters.

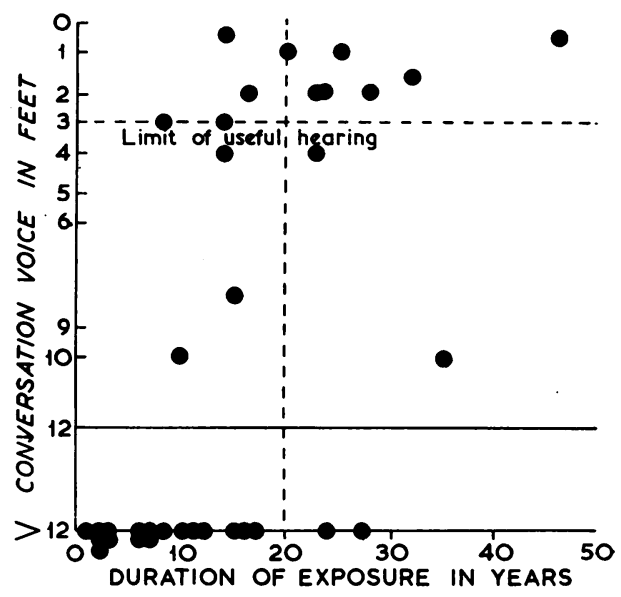

FiG. 2.-Stampers.

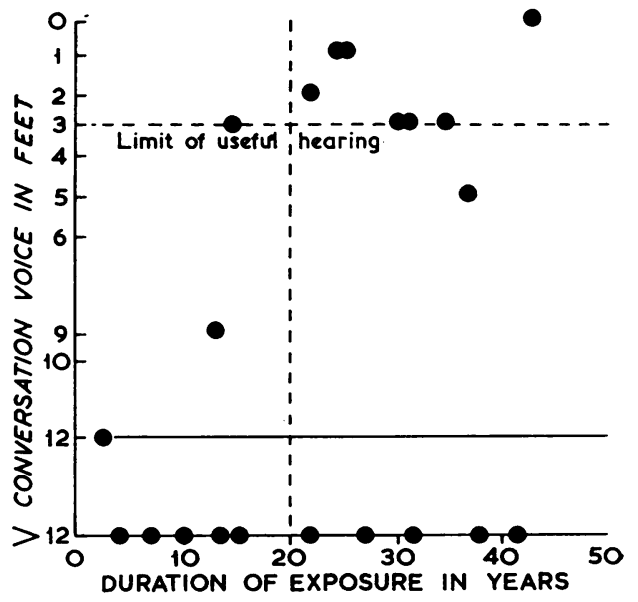

Fig. 3.-Platers. 




FIG. 4.-Headers.



FIG. 5.-Welders, template makers, and machine operators.

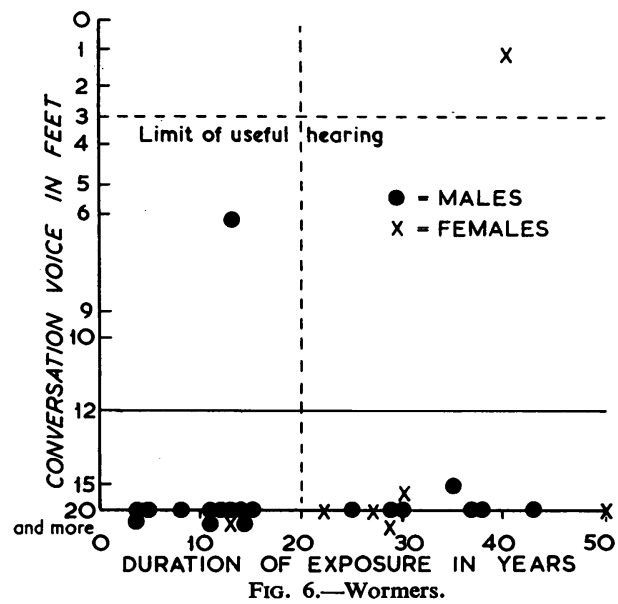



Fig. 7.-Turners.

voice at 3 feet and at 10 feet bears a definite relationship to the intensity of the noise in the trade, but Table 2 shows that the same relationship is not apparent for the men with less than 20 years' exposure.

Table 3 summarizes the audiometric results. In at least $70 \%$ the maximum loss occurred at a single

TABLE 3

FREQUENCY OF MAXIMUM LOSS OF HEARING AT VARIOUS FREQUENCIES IN 190* WORKERS

\begin{tabular}{|c|c|c|c|c|c|}
\hline & & & & $\begin{array}{l}\text { No. of } \\
\text { Men }\end{array}$ & $\begin{array}{c}\text { Percentage } \\
\text { of Total }\end{array}$ \\
\hline $\begin{array}{l}2896 \text { c.p.s. } \\
2896 \text { and } 4096 \text { c.p.s. } \\
4096 \text { c.p.s. } \\
4096 \text { and } 5792 \text { c.p.s. } \\
5792 \text { c.p.s. } \\
2896 \text { to } 5792 \text { c.p.s. } \\
\text { Complete loss above }\end{array}$ & $\begin{array}{l}\cdots \\
\therefore \\
\therefore \\
\therefore \\
2048 \mathrm{c} .\end{array}$ & $\begin{array}{l}\cdots \\
\cdots \\
\cdots \\
\cdots \\
\cdots \\
\text { p.s. }\end{array}$ & $\begin{array}{l}\cdots \\
\cdots \\
\cdots \\
\cdots \\
\cdots\end{array}$ & $\begin{array}{r}53 \\
32 \\
61 \\
14 \\
18 \\
8 \\
4\end{array}$ & $\begin{array}{r}28 \\
17 \\
32 \\
8 \\
9 \\
4 \\
2\end{array}$ \\
\hline
\end{tabular}

*Excluding one case with a normal audiogram.

frequency. In the remainder the maximum loss was equal at two or more frequencies, e.g. a flatbottomed " $\mathrm{C}_{5}$ dip." The maximum loss most often occurred to tones at a frequency of 4,096 c.p.s. $(34 \%$ ), but a maximum loss to tones at a frequency of 2,896 c.p.s. was almost as common $(28 \%)$. If, in addition, the audiograms with a " $\mathrm{C}_{5}$ dip" at 5,792 c.p.s. and those with a flatbottomed " $\mathrm{C}_{5}$ dip" are considered, the mean value for the position of the dip lies at less than 4,096 c.p.s.

The development of the " $\mathrm{C}_{5}$ dip" is demonstrated by examination of the series of audiograms of which Figs. 8 to 13 are a selection. The " $C_{5}$ dip" at first appears as a steep-sided notch of usually one or occasionally up to two octaves in 


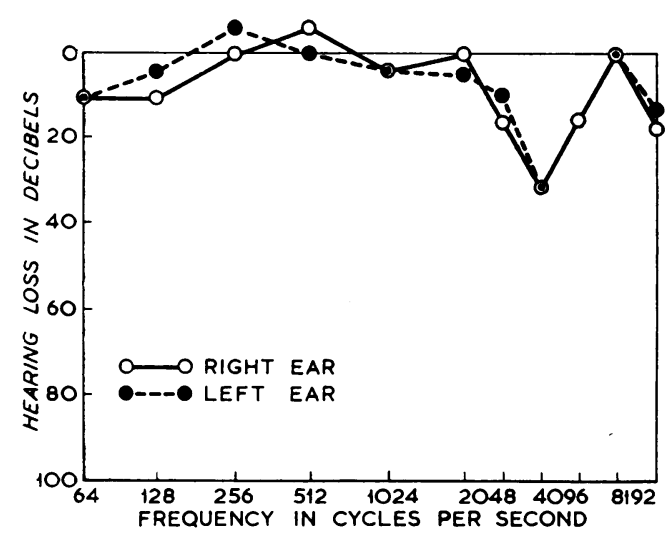

Fig. 8.-Stamper, age 29. Duration of exposure, three months. Whispered voice heard at $10 \mathrm{ft}$. distance from both ears.



Fig. 9.-Stamper, age 22. Duration of exposure, one and a half years. Whispered voice heard at $10 \mathrm{ft}$. distance from both ears.

width (Fig. 8). With longer exposure to noise the apex of the dip descends (Fig. 9), and in most cases the sides remain steep until the hearing loss at the apex of the dip lies between 60 and $80 \mathrm{db}$ (Fig. 10). Up to this stage the hearing at other frequencies is not affected except in the case of the stampers, where some loss occurs at frequencies below 2,048 c.p.s. The hearing at 8,192 c.p.s. is within normal limits for the age of the individual. At a later stage the sides of the " $C_{5}$ dip" become less steep due to losses at frequencies immediately above and below, with some additional loss at a frequency of 11,584 c.p.s. (Fig. 11). The widening of the mouth of the dip, together with a continued increase in its depth, continues (Figs. 11 and 12) until total loss of hearing to tones above a frequency of 1,024 or 2,048 c.p.s. occurs (Fig. 13). In the few audiograms obtained showing this extreme degree of deafness there was an equal loss of hearing at frequencies of 64,128 , and 256 c.p.s.

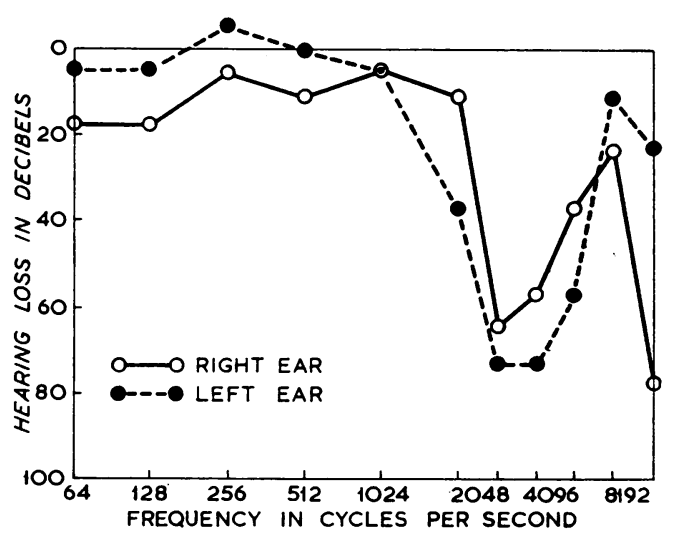

Fig. 10.-Stamper, age 36. Duration of exposure, 12 years. Whispered voice heard at $\frac{R t}{\mathrm{Lt}}=\frac{7}{4} \mathrm{ft}$. distance.

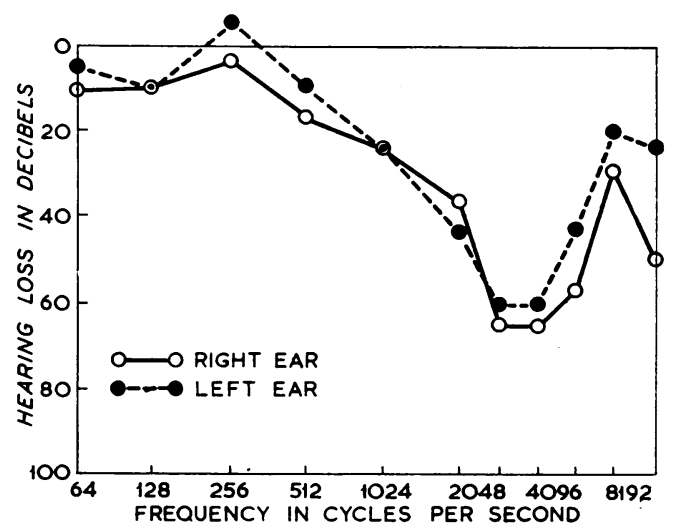

FIG. 11.-Stamper, age 27. Duration of exposure, eight years. Whispered voice heard at $\frac{\mathrm{Rt}}{\mathbf{L t}}=\frac{1}{1.5} \mathrm{ft}$. distance. Conversational voice heard at more than $10 \mathrm{ft}$. distance from both ears.

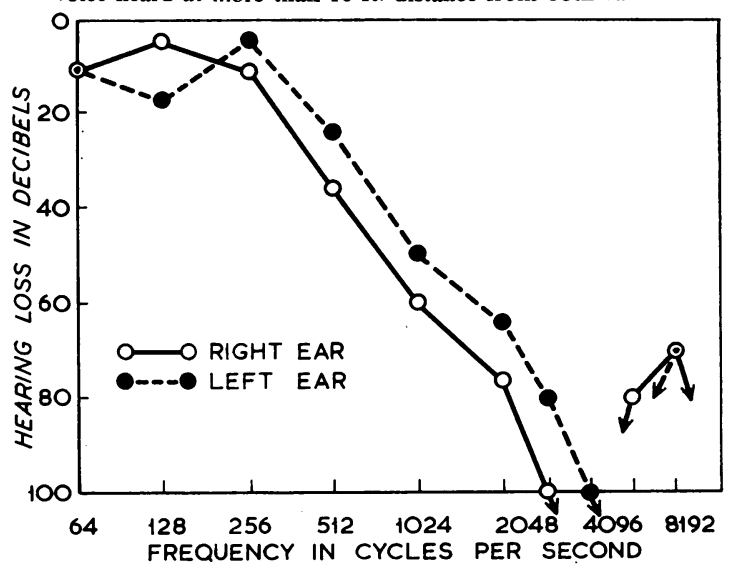

FIG. 12.-Chipper, age 60. Duration of exposure, 43 years. Whispered voice heard at $\frac{\mathrm{Rt}}{\mathrm{Lt}}=\frac{\text { Contact }}{0.25} \mathrm{ft}$. distance. Conversational voice heard at $\frac{R t}{L t}=\frac{1}{2} \mathrm{ft}$. distance. 


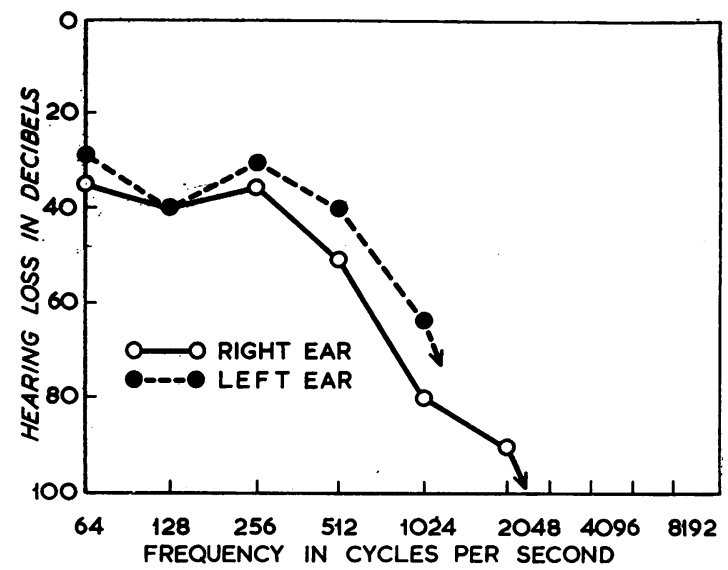

Fig. 13.-Chipper, age 60. Duration of exposure, 46 years. Whispered voice not heard. Conversational voice heard at $\frac{\mathbf{R t}}{\mathbf{L t}}=\frac{\text { Contact }}{\mathbf{0 . 2 5}} \mathrm{ft}$. distance.

\section{Relation of External and Middle Ear Conditions to Occupational Deafness}

Cerumen.-Meatal occlusion of long standing was found in one subject only. His audiogram for the right ear (Fig. 14) made after the removal of wax showed little loss of hearing, whereas the left ear in which there was no wax showed loss in the $C_{5}$ region.

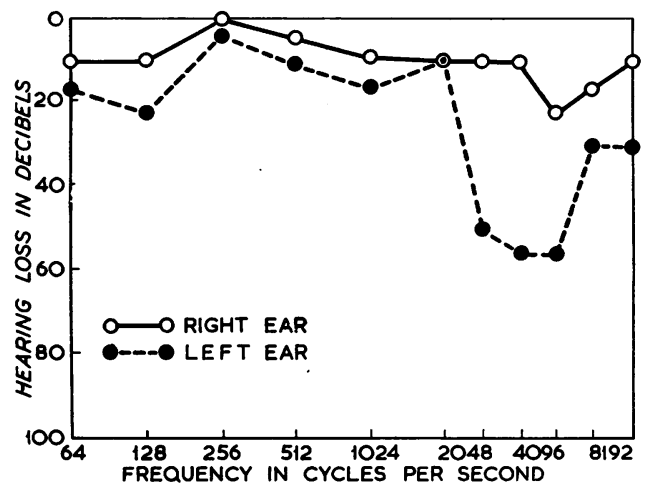

FIG. 14.-Welder, age 31. Duration of exposure, 16 years. Meatal occlusion of long standing in right ear. Audiogram made after removal of wax.

Chronic Adhesive Otitis Media.-Out of a total of 438 ears in 219 subjects, 19 ears in 17 subjects were the site of active suppuration, and 58 ears in 38 subjects showed scarring or a dry perforation of the tympanic membrane. The audiograms of the cases with unilateral active or healed otitis media showed with four exceptions a hearing loss in the 2,896 to 5,792 c.p.s. frequency range equal in both ears. The hearing for the low tones was either the same in the both ears or diminished by the presence of otitis media. The exceptions just mentioned, two cases of unilateral active otitis media and two cases of healed otitis media, showed greater hearing losses in the 2,896 to 5,792 c.p.s. range in the unaffected ears of from 20 to $40 \mathrm{db}$.

Peyser (1943) found that the hearing in ears affected by active otitis media was more readily fatigued by experimental exposure to pure tones of high intensity, but Theilgaard (1951) did not confirm this finding and suggested that a conduction deafness due to middle ear disease offered protection to the organ of hearing of workers in noisy surroundings. It was not possible in this study to show an increased susceptibility to damage by traumatic noise of an ear affected by disease but the four exceptions mentioned show that in a small proportion of cases otitis media may afford some protection to the cochlea in the 2,896 to 5,792 frequency range. No opinion is expressed as to a protective effect on the cochlea at the speech frequencies 512 to 2,048 c.p.s. The loss of hearing to these tones is usually more rapid from otitis media than from acoustic trauma although the final result may be less severe.

\section{Recovery of Hearing after Leaving Work}

Forty-five per cent. of all the subjects (86 out of 191) stated that their hearing improved after leaving their work. Some noticed the improvement within half-an-hour to four hours. In others the improvement in hearing was less marked and only noticeable over a period of a few days or several months. The subjective improvement in hearing following absence from work was generally more marked during the earlier months or years of a worker's exposure to noise. To obtain an objective assessment of the actual recovery which may have occurred, a few workers were re-examined after a period away from work. The re-examination was made at the start of the work period and before the subject had entered the workshop. Table 4 summarizes the findings.

Apart from two cases (Nos. 4 and 12) there was no significant* improvement after 12 days' rest from noise at either the speech frequencies or in the " $\mathrm{C}_{5}$ dip". Experimental work indicates that temporary deafness from fatigue of the end organ due to loud tones is rapidly lost, mostly within a few minutes but to a lesser extent in a few hours. As already stated, the first audiograms were made after the subjects had been in quiet surroundings for 20 to 30 minutes. The relatively slight changes

\footnotetext{
*A gain or loss of 10 decibels is considered to be within the margin of
} error in pure tone audiometry. 
TABLE 4

RECOVERY OF HEARING AFTER ABSENCE FROM WORK

\begin{tabular}{|c|c|c|c|c|c|c|c|c|}
\hline \multirow{2}{*}{ Case No. } & \multirow{2}{*}{$\begin{array}{c}\text { Duration of } \\
\text { Exposure in } \\
\text { Years }\end{array}$} & \multicolumn{3}{|c|}{$\begin{array}{l}\text { Average Loss (db) at } 2896,4098, \\
\text { and } 5792 \text { c.p.s. }\end{array}$} & \multicolumn{3}{|c|}{$\begin{array}{l}\text { Average Loss (db) at } 512,1024 \text {, and } \\
2048 \text { c.p.s. }\end{array}$} & \multirow{2}{*}{$\begin{array}{l}\text { Duration of } \\
\text { Rest }\end{array}$} \\
\hline & & $\begin{array}{c}\text { On First } \\
\text { Test }\end{array}$ & $\begin{array}{c}\text { Re-test after } \\
\text { Rest }\end{array}$ & Gain & $\begin{array}{c}\text { On First } \\
\text { Test }\end{array}$ & $\begin{array}{c}\text { Re-test after } \\
\text { Rest }\end{array}$ & Gain & \\
\hline $\begin{array}{r}1 \\
2 \\
3 \\
4 \\
5 \\
6 \\
7 \\
8 \\
9 \\
10 \\
11 \\
12\end{array}$ & $\begin{array}{c}1 \\
32 \\
12 \\
14 \\
1 \frac{1}{2} \\
8 \\
35 \\
\frac{1}{4} \\
2 \frac{1}{2} \\
1 \frac{1}{3} \\
27^{\frac{1}{4}}\end{array}$ & $\begin{array}{l}28 \\
83 \\
45 \\
68 \\
36 \\
36 \\
71 \\
33 \\
35 \\
42 \\
26 \\
55\end{array}$ & $\begin{array}{l}27 \\
83 \\
45 \\
62 \\
36 \\
32 \\
74 \\
40 \\
27 \\
39 \\
29 \\
35\end{array}$ & $\begin{array}{r}+1 \\
0 \\
0 \\
+6 \\
0 \\
+4 \\
-3 \\
-7 \\
+8 \\
+3 \\
+3 \\
+20\end{array}$ & $\begin{array}{r}16 \\
40 \\
19 \\
33 \\
2 \\
20 \\
18 \\
8 \\
14 \\
13 \\
13 \\
17\end{array}$ & $\begin{array}{r}12 \\
40 \\
15 \\
19 \\
5 \\
20 \\
19 \\
14 \\
9 \\
13 \\
11 \\
8\end{array}$ & $\begin{array}{r}+4 \\
0 \\
+\quad 4 \\
+14 \\
-\quad 3 \\
0 \\
-\quad 1 \\
-6 \\
+\quad 5 \\
0 \\
+\quad 2 \\
+\quad 5\end{array}$ & 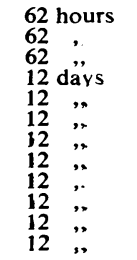 \\
\hline
\end{tabular}

in the majority of the second set of audiograms would appear to confirm this experimental finding and indicate that little restoration of hearing could be expected if the worker were to change to a quiet occupation.

\section{Adaptation of Hearing to Noise}

It is a common experience for visitors conducted round a noisy factory to have difficulty in hearing speech. The high level of ambient noise effectively masks the speaker's voice. Yet it is well known among factory managers (who conduct such visitors) that those who spend their working hours in noise can readily hear each other without shouting. It is probable that an ability to lip read plays a part. Thirty-seven per cent. (71 out of 191) of the subjects examined in this investigation were conscious of lip reading during working hours. It was noticeable that in well lit factories where the workers can see each other over the machines, as in the screw factory, $56 \%$ (45 out of 79 ) of the operatives admitted to lip reading at work. Where the standard of illumination was low and the workers could not, by the nature of the work and the machinery, see each other's faces, as among chippers, platers, and stampers, only $20 \%$ (26 out of 127) admitted to lip reading. There must be, however, another mechanism whereby the subject can hear speech through the noise. Proof of this was obtained during a visit to a cotton weaving shed containing approximately 1,000 looms in motion. While the ambient noise was not as intense as, say, the heading section of a screw mill, the visitor experienced some difficulty in hearing speech, which was only intelligible when spoken in a raised voice close to the ear. A musical entertainment programme was being relayed during the visit and amplified through loud speakers in the shed. The visitor, by standing close to a loud speaker, was just able to hear the bass accompani- ment of the musical composition. The air played by the treble instruments was effectively masked by the noise of the looms. Yet a middle aged female weaver could easily recognize the composition and stated she could hear the words of a song when sung by a soprano voice.

This adaptation of hearing to speech in noise is to some extent lost during periods of rest. Thirtysix per cent. (69 out of 191) of the subjects stated that after two days at the weekend or after the annual 12 days' holiday, they found difficulty in hearing speech for the first half to four hours after beginning work again.

Most of the workmen who had been severely deafened by occupational noise experienced the phenomenon of paracusis willisiana* in the factory but not in other noisy surroundings, such as trains or omnibuses. While it is probable that they could hear speech better in the factory because of a rise in the intensity of the speaker's voice, the ability to hear speech through the noise of their work (also shown by less deafened but seasoned workmen) may well have some effect. It is, therefore, suggested that the phenomenon of adaptation of hearing to speech in noise is of central rather than cochlear origin.

\section{Other Subjective Effects of Noise}

Tinnitus.-This was a common complaint. While most workers were free from it at the time of examination, $40 \%$ of all subjects (78 out of 191) could remember suffering from it during the early years of their work in a noisy trade. High pitched and ringing, it was always slight in intensity, never caused loss of sleep, and was rarely loud enough to be heard while at work.

Vertigo.--Vertigo induced by noise was complained of by only two subjects, both platers, with

*The ability of a deaf person to hear speech easily in noisy, but not in quiet, surroundings. 
normal ears. It occurred when they were inside a small boiler which was being hammered on the outside by heavy sledge hammers by four men. Nausea did not result and the vertigo passed off within a few minutes of emerging from the boiler. Considerable pain was experienced in the ears from the noise, a rare complaint amongst workers in noisy occupations.

Poor Concentration, Headache, or Irritability.None of these ascribed to occupational noise was often complained of and was more usually due to dissatisfaction with the nature of the work or other extraneous factors. It was well recognized among the foremen that if a workman objected to the noise of the work, he would soon change to a quieter job. A high proportion of new hands left such noisy work from this cause, but if the worker could persist at the work for a week or two, acclimatization usually took place. The subject was then able to ignore the noise and found it neither irritating nor unpleasant. In fact many stampers found the noise of their trade soothing.

Awareness of Risk of Occupational Deafness.With few exceptions, workers in the boiler-making and stamping trades were aware of the high incidence of occupational deafness, but were not apparently perturbed by the prospect. The insidious onset of deafness which resulted in a man being unaware of the degree of his hearing loss and the relatively high proportion of old hands with serviceable hearing engenders a spirit of laissez faire. The wearing of protective devices in the ear was observed only in the boiler-making trade. Even here in the noisiest section (the chippers) only four out of 14 men habitually wore wool plugs for the express purpose of protection from noise. In the same group no less than three men merely inserted the plugs to prevent the ingress of dust. Out of the remaining 50 boiler-makers who were examined, only six habitually wore wool plugs.

\section{Prevention of Occupational Deafness}

The ideal remedy for the prevention of occupational deafness would be to eliminate injurious noise at its source. Improved designs of machines and their mountings have already done much to help. Technical advances in the method of manufacture may diminish noise but the reverse is often the case. For example, the electrical welding of steel plates, which is to a limited extent supplanting the lapped riveted joint, necessitates the extremely noisy process of chipping. The reduction of noise at the source has thus only limited possibilities.
The reduction of reflection and reverberation of noise by sound proofing surfaces and erecting baffle walls have in certain instances been effective, but again scope is limited.

There remains a third alternative, the acoustic insulation of the worker's ear by wearing a protective device. Two main types have been described, the meatal plug and the ear "muff". The former may consist of dry cotton wool (commonly used but of little value), cotton wool impregnated with vaseline or " plasticine", or rubber. Vaseline impregnated cotton wool is stated by Fowler (1940) to produce a relatively constant attenuation of $20 \mathrm{db}$ for frequencies below 1,000 c.p.s. and $30 \mathrm{db}$ for frequencies above 1,000 c.p.s. Of the numerous types of rubber ear plugs, the $\mathrm{V}-51 \mathrm{R}$ ear warden provides an acoustic insulation of 25 to $30 \mathrm{db}$ or more at the high end of the audiometric frequency spectrum (Taylor, 1947). An example of the second type of ear protector is the Rüedi defender (Rüedi and Furrer, 1946). Designed primarily for use by gun crews, it consists of a metal box with a rubber flange on the edge fitting closely to the head and covering the whole of the external ear. The outer wall of the box is perforated by several fine holes. The size of the holes and the capacity of the box are calculated to the desired resonance, frequency, and damping. The damping reduces the steepness of the front of the sound pressure wave and also the maximum pressure amplitude operating on the ear drum. The hearing loss obtained when the defender is worn is insignificant at the middle and lower frequencies but above 2,000 c.p.s. amounts to 25 to $30 \mathrm{db}$. An experimental test of the Rüedi defender on several subjects with normal hearing under the noise conditions of a boiler shop showed that considerable aural fatigue from noise occurred when the defender was worn.

Both types of protective device have their disadvantages. The meatal plug, while giving a high degree of protection, is unsuitable in cases of otitis media or otitis externa. It may irritate the meatal skin, particularly in hot and dusty trades. Repeated insertion will drive plugs of wax further into the meatus. It may allow noise to reach the ear unless correctly adapted to the shape of the meatus, particularly where the meatal canal is oval in crosssection. It is liable to cause discomfort when worn regularly for long periods. Owing to its small size a rubber plug is easily lost and must be regularly cleansed to avoid the risk of infection. The Rüedi defender has none of these disadvantages except that in very hot occupations excessive moisture will accumulate inside the box and may exacerbate a pre-existing dermatitis. In the boiler-making and 
ship-building trades, where the wearer often has to work in a confined space, some modification of the head band would be necessary to allow for the wearing of a protective cap.

The Rüedi ear defender was designed to allow the hearing of speech. Although necessary for a gunner, a workman in a noisy factory only occasionally needs to hear spoken instructions. When the fine holes of the defender are occluded by a layer of "plasticine" a considerable improvement in the sound occlusion results and little aural fatigue is caused on exposure to loud noise. In view of the previously mentioned advantage of the box type of defender over the meatal plug it would seem desirable that further experiments should be carried out with ear " muffs" of various materials.

\section{Conclusions}

Minimum Values for Harmful Noise.-Table 1 shows that a larger proportion (26 out of 49 ) of the men employed in chipping, riveting, stamping, plating, and heading became deafened to speech at more than 3 feet after 20 years' exposure, whereas of those engaged in worming and turning, only one out of 13 of the former and none out of 24 of the latter are deafened to a like degree. In the heading section four out of 14 men were so deafened.

Although the size of the samples in each of these groups is small it would appear that the risk of damage to hearing is considerably greater in the heading section than in the worming section. The noise level measurements in the heading, worming, and turning sections vary from 100 to 112 phons. It would appear therefore that noises of an intensity of 100 to 112 phons represent the border line between that which is harmless to hearing and that which is harmful to an appreciable proportion of subjects.

It is therefore suggested that it is only when the overall noise level exceeds the region of 105 to 108 phons that serious damage to hearing is likely to occur in an appreciable proportion of the population exposed. Noise less intense than 105 phons will probably cause damage only to the hearing of the most susceptible subjects.

Prevention of Occupational Deafness.-Mention has already been made of the limited possibilities of the reduction of noise at its source or by reflection or reverberation. Where reduction to harmless levels cannot be effected by these means, the ears of the individual worker must be protected. Furthermore, the degree of protection must be related to the intensity of the noise level in which he works and the susceptibility of the particular individual.
When the intensity of the noise is more than 105 to 108 phons, protective devices should be worn by all workers. As pointed out by Perlman (1945) a device which gives an insulation of $30 \mathrm{db}$ when worn in an ambient noise of $120 \mathrm{db}$ wili probably reduce the noise reaching the cochlea by $30 \mathrm{db}$, e.g. to $90 \mathrm{db}$. An additional protection of, say, $15 \mathrm{db}$ will be required for safety. Hence a protective device with an insulation value of $30 \mathrm{db}$ will be adequate for the worker in a noise of $110 \mathrm{db}$ but will fail to give adequate protection at a higher noise level of $130 \mathrm{db}$.

The average workman is notoriously careless in the use of safety devices, particularly where these are provided to prevent uncommon accidents or disease of delayed onset. Thus MacLaren and Chaney (1947) found that of a group of workmen provided with ear defenders, only one third used them regularly, one third used them occasionally, and one third discarded them soon after issue. Education of the workman on the risks involved and official recognition by legislation would doubtless effect improvement.

Any form of ear defender worn by the worker whose hearing is very susceptible may be inadequate to prevent loss of hearing if he works in very intense noise. Furthermore, such a susceptible individual working in a source of noise of less than 105 phons (but probably of more than 90 phons) will, if he is to continue in such work, require protection. To discover such susceptible individuals in any occupational group at risk before permanent loss of hearing results, it will be necessary to devise a reliable pre-employment test for susceptibility. Failing this, such individuals should be weeded out in the earliest stages of their deafness before permanent loss of hearing results. Theilgaard (1949) suggests that previously described tests are likely to be unreliable, so, for the present, reliance must be placed on the latter method.

Grove (1949) presents the views of the SubCommittee on Industrial Noise of the Committee on Conservation of Hearing set up by the American Academy of Ophthalmology and Otolaryngology. $\mathrm{He}$ recommends that every workman engaged in a job where the noise level exceeds $90 \mathrm{db}$ should have a pre-employment audiometric examination and be re-tested after one week and subsequently at stated intervals. Any workman who complains of tinnitus after working in a noisy environment should have his hearing re-tested. If on any of these re-tests it is found that an average loss of $10 \mathrm{db}$ at 3,000 to 6,000 c.p.s. has occurred, he should be forced to wear a protective device or be transferred to a less noisy job. 


\section{Summary}

A report is presented on an investigation into the hearing of 219 men and women employed in several noisy engineering trades. Twenty-eight workers were found to be suffering from bilateral ear disease or deafness not due to noise. Of the remaining 191, all except one man were found to have hearing losses due to noise which could be demonstrated either by speech or pure tone audiometric tests. The tests were carried out at the factories during working hours.

After 20 or more years' exposure to the noise of their work, nine out of 12 chippers and riveters, seven out of 11 stampers (drop forgers), six out of 12 boiler plate fitters, and four out of 14 heading machine operators who were examined were unable to hear speech at more than 3 feet distance in either ear.

Reference is made to noise level measurements observed by the Physics Department of the National Physical Laboratory in the factories where the hearing tests were carried out. Figures from their report suggest that only when the overall noise level exceeds 105 to 108 phons is serious damage likely to be caused to the hearing of an appreciable proportion of the workmen. Noise less intense than 105 phons will probably cause damage to the hearing of only a small group of individuals most susceptible to injury.

Observations are also made on the recovery of hearing after a period of rest from work, the phenomen of adaptation of hearing for speech in ambient noise, and other subjective effects of noise.

I am indebted to $\mathrm{Mr}$. Terence Cawthorne for his advice throughout the investigation; to Dr. Donald Stewart for advice and for arranging the field trials; to Dr. W. Jeaffreson Lloyd of Guest Keen and Nettlefolds Ltd ; and to the Directors and Staff of Messrs. Edwin Danks Ltd, John Garrington and Sons Ltd, and Guest Keen and Nettlefolds Ltd.

\section{REFERENCES}

Bunch, C. C. (1937). Laryngoscope, St. Louis, 47, 615.

(1942). J. Amer. med. Ass., 118, 588.

Caussé, R., and Falconnet, P.(1947). Ann. Oto-laryng., Paris, 64, 436. Fosbroke, J. (1830-31). Lancet, 1, 533, 645, 740, 777, 823.

Fowler, E. P., Sr. (1928). Arch. Otolaryng., Chicago, 8, 151.

Fowler, E. P., Jr. (1940). Acta oto-laryng., Stockh., 28, 283.

Grove, W. E. (1949). Industr. Med., 18, 25.

Larsen, B. (1939). Acta oto-laryng., Stockh., Suppl. No. 36

MacLaren, W. R., and Chaney A. L. (1947). Industr. Med., 16, 109.

Nussdorfer, R. (1942). Oto-rino-laring. ital., 12, 431 .

Nussdorfer, R. (1942). Oto-rino-laring. ital.,
Perlman, H. B. (1945). Ann. Surg., 122, 1086.

Perlman, H. B. (1945). Ann. Surg., 122, 1086. 351.

Peyser, A. (1943). Acta oto-laryng., Stockh., 31, 351.

Rüedi, L., and Furrer, W. (1946). J. acoust. Soc. Amer.,
Taylor, H. M. (1947). Laryngoscope, St. Louis, 57, 137.

Taylor, H. M. (1947). Laryngoscope, St. Louis, 57, 137.

Theilgaard, E. (1949). Acta oto-laryng., Stockh., 37, 347. Normal Hearing and in Noise Workers (Weavers). Thesis. Munksgaard, Copenhagen.

Weiss, J. A. (1947). Ahn. Otol., St. Louis, 56, 175. 